Research Article

\title{
Research on the Collaborative Application of BIM in EPC Projects: The Perspective of Cooperation between Owners and General Contractors
}

\author{
Chengshuang Sun $\mathbb{D}^{1},{ }^{1}$ Min Wang $\mathbb{D}^{1},{ }^{1}$ and Fengyong Zhai $\mathbb{D}^{2}$ \\ ${ }^{1}$ School of Urban Economics and Management, Beijing University of Civil Engineering and Architecture, Beijing 102616, China \\ ${ }^{2}$ School of Management, Harbin Institute of Technology, Harbin 150001, China \\ Correspondence should be addressed to Fengyong Zhai; fyzhai@hit.edu.cn
}

Received 31 May 2021; Revised 21 July 2021; Accepted 13 August 2021; Published 26 August 2021

Academic Editor: Loke Foong

Copyright (c) 2021 Chengshuang Sun et al. This is an open access article distributed under the Creative Commons Attribution License, which permits unrestricted use, distribution, and reproduction in any medium, provided the original work is properly cited.

\begin{abstract}
As an effective way to reduce costs and increase efficiency of EPC projects, BIM technology has drawn a lot of attention in numerous countries. Existing studies have failed to reveal the BIM decision-making mechanisms of owners and general contractors in EPC projects in a dynamic method. This study investigates the underlying logic of the collaboration application of BIM by analyzing the dynamic behaviors of owners and general contractors based on evolutionary game model. The results show that the most effective suggestions to promote the BIM collaboration application in EPC projects are "increasing the proportion of BIM application initially strategies," "increasing incremental revenue of BIM collaborative application," "reducing costs of BIM collaboration application," "avoiding excessive hitchhiking," and "establishing reasonable reward and punishment mechanism." On the basis of numerical simulation to illustrate the influence of the different initial strategies and parameters on the final decision in different situations, five solutions were proposed for the effective BIM collaboration application between owners and general contractors. This article can facilitate researchers pondering the dynamics of collaboration among stakeholders in projects, and it can also facilitate participants picking up proper strategies for improved collaboration.
\end{abstract}

\section{Introduction}

Several challenges are restricting the development of the construction industry, such as low profit, enormous consumption of resources, massive waste, and low productivity [1]. The combination of Engineering Procurement Construction (EPC) and building informatization is a solution that can be implemented so as to mitigate these challenges. The EPC model allows general contractors to control projects design, procurement, construction and provide specialized and commercialized services [2], which has become the most popular project delivery strategy for industrialized construction [3]. The EPC mode effectively solves the mutual restriction and disconnection of design, procurement, and construction under other delivery modes, which is contributing to the overall planning and coordinated operation of the entire project. Nevertheless, the projects that adopt the EPC usually have an extended construction period and complex management, which often experience cost and schedule overrun [4]. And general contractors need to undertake greater risks. Building Information Modeling (BIM) that leads building informatization is a technology that supports the design, construction, material manufacturing, and management of projects by creating accurate virtual models of buildings, helping integrate design and construction to achieve better functional performance of buildings while reducing costs and duration [5]. Based on BIM collaborative management platform, the data and construction plans are integrated and shared effectively in EPC projects. Eventually, the management process of data creation, circulation, analysis, and decisionmaking can be fully monitored, which improves the quality and efficiency of project management $[6,7]$. 
Although BIM holds the promise of considerably advancing the architecture, engineering, and construction market worldwide, its widespread acceptance and adoption in EPC projects is still an unresolved issue. The application level of BIM in the project is not only related to BIM investment, technical capabilities, but also closely depend on the working practices and ethos of participants in the project [8]. Engineering projects that become more and more complicated have put forward higher requirements for cooperative decision-making ability and cooperative level [9]. Since the 1980s, the spirit of collaboration and cooperation has been mentioned by many scholars in engineering projects. They believe that if project stakeholders can collaborate and cooperate, conflicts of interest and disputes will be reduced [10]. There are many participants in the EPC project, including owners, general contractors, subcontractors, suppliers, and other stakeholders, whose decisions would be critical in affecting the actual results of BIM adoption and application. The owners often play a dominant role in construction. And the general contractors are the main body chargeable for the design and implementation of the projects, while responding to various risks from political, economic, and environmental aspects in the EPC project [11]. Thus, owners and the general contractors are selected as the two sides of the game in this study. For BIM application, the owners expect to obtain high-quality engineering products through BIM with a relatively reasonable investment; the general contractors aim to complete the project with the help of BIM at low cost. The conflicting positions will produce to opportunism, in which both parties do anything to realize higher gains regardless of the expense to the other [12]. Recently, researches focused on identifying BIM application and the obstacle factors of BIM's promotion. And BIM technology diffusion is explained from a static perspective. There have been no studies in the context of EPC that consider responses of owners and general contractors to BIM application using two-population evolutionary game. So, the main contributions of our research are twofold. First, this work investigates the dynamic collaboration decision process of owners and general contractors, which played a positive role in advancing the management efficiency and level of the projects. Second, the evolutionary game theory employed in this study can facilitate various applications. Evolutionary game theory can be extended to explore the collaboration between other BIMrelated stakeholders.

\section{Literature Review}

2.1. BIM Application in EPC Projects. BIM technology, as one of the core technologies of architecture digitalization, is widely concerned by government, enterprises, industry organizations and scholars, etc. Governments around the world are actively promoting the implementation of BIM in their own countries and have made clear provisions for the application process of BIM [13-15]. After nearly half a century of development, BIM plays an active role in the whole life cycle of construction projects. The study found that $75 \%$ of companies that adopt BIM have obtained considerable returns on investment [16]. EPC projects are characterized by high complexity and difficulty in coordination. On the one hand, the BIM-based collaborative management platform can promote exchanges between different participants in EPC projects; on the other hand, it can achieve collaborative cooperation, such as deepening design and resource management [17]. Parametric design improves the speed of model generation and modification and conducts conflict detection and evaluation during deepening design to find and solve problems in time $[14,18]$. Before the construction of EPC projects, BIM visualization and construction simulation are utilized to assist in the completion of site planning, machinery configuration, and resource and material supply [17]; thus, the best construction plan was chosen. Integrate BIM and ecommerce into the material procurement process, fully obtain data such as suppliers and material prices, and reduce material procurement costs [19]. By providing relevant information (schedule, cost, material inventory, and spatial relationship), BIM enables participants to collaborate efficiently throughout the EPC project life cycle $[20,21]$.

The current experience of integrating BIM into the EPC project management process is less, and also the application system has not kept up with the pace of development. The application level of BIM in EPC projects not only depends on the project teams' technology, financial, organization, management issues, and related legal issues [13, 22-24], but also closely related to the attitudes of other participants towards BIM. They cannot genuinely cooperate even if they jointly adopt BIM technology because various enterprises seek to maximize their own interests [25]. In addition, BIM investment differentiation and information asymmetry among numerous parties make it difficult to realize collaborative application of BIM, which is likely to cause waste of resources and fail to achieve overall optimization. Therefore, clarifying the game relationship between participants is helpful to solve the problems existing in the collaborative application of BIM and enable all parties to obtain higher benefits.

\subsection{Evolutionary Game to Studying BIM Application} Behavior. Both parties may conceal real information, resulting in the occurrence of game phenomena under information asymmetry in EPC projects. BIM can facilitate the data exchange of different disciplines and the collaboration of different stakeholders [26]. With the help of game theory, the behavioral strategies of different behavior subjects regarding the application of BIM can be analyzed. Yuan and Yang [27] introduced game theory into explaining BIM adoption and diffusion first time and identified two influential factors affecting BIM adoption decisions, including BIM adoption efficiency and adoption incentives. Sun and Wang [28] analyzed the interaction between BIM's promotion and project owners, contractors' interest game by combining asymmetric information theory and game theory, and suggested project owners should choose BIM at proper stage but not the most advanced one and contractors' effort cannot be ignored when promoting BIM. Evolutionary 
game theory is an effective method of policy making. Zheng et al. [25] developed an outcome-linked benefit sharing model that considers sharing joint BIM benefits among stakeholders including designers, contractors, and clients by modeling stakeholders' behaviors as evolutionary games within a principal-agent formalism. Based on evolutionary game, Runrun and Richards [29] studied the collaborative management mechanism of BIM with actual cases. Du et al. [30] researched the selection strategy of BIM from the perspective of moral hazard. Wang et al. [31] discussed the process and method of cooperative innovation between the construction contractors and diverse subcontractors, and it focuses on the analysis of the influence of cooperative profit distribution, spillover effect, innovation subsidies, and cooperation risk sharing for evolutionary stable strategy. It can be seen from the above literature that the promotion of BIM in projects requires the coordinated promotion of multiple stakeholders.

The systematic review of existing studies shows us a giant picture that EPC, as a popular project delivery system, along with BIM provides more possibility to improve the project performance. The game between participants and collaboration is an important reason for the level of BIM adoption in EPC projects. Very few studies have targeted on the BIMbased selection strategies from the perspective of EPC contract model and tracked how these interactive behaviors evolve dynamically. And the strategic selection of owners and general contractors, as core stakeholders within the EPC project, directly determines the appliance level of BIM. Therefore, the research attempts to reveal the cooperative application mechanism of BIM between owners and general contractors in EPC projects through evolutionary game. It has important practical and theoretical value for driving participants to settle on "positive collaboration."

\section{Research Methodology}

The interactive behavior of strategies selection related to BIM application is a complicated dynamic process. It is impossible to require each player to fully know about the competitors' information at the beginning. Each player selects strategies through constant trial and error, learning, imitation, and correction behavior. The evolutionary game model replaced absolute rationality with bounded rationality [32] and is combined with evolutionary dynamic, which provides a quantitative analysis of the framework and predicts the behavior of different participants [33, 34]. An evolutionary game model is a strategic interaction that includes the elements such as populations, payoff function, dynamics, and equilibrium. The replicator equation and evolutionarily stable equilibrium (ESS) as two core concepts of the evolutionary game model can be taken advantage of dynamically capturing the interactive behavior and describing the evolution state quo. The replicative dynamic equation is ordinary differential equation $\dot{x}_{i}=x_{i}\left(F_{i}(x)-\right.$ $\bar{F}(x))$ to describe strategy evolution, where $x$ can be regarded as the state of the system, $x_{i}$ is the frequency of strategy $i$ in the population, $F_{i}(x)$ is the adaptability of strategy $i$ when the system state is $x$, and $\bar{F}(x)$ is the average adaptability of the population under state $x$. The ESS is robust in that the population can eliminate any small mutation within a small group. In general, evolutionary equilibrium strategies can withstand a certain degree of deviation, and behaviors that deviate from this strategy will be eliminated. Evolutionary game theory takes groups as the subjects, emphasizing the dynamic equilibrium among different kinds of groups. It is regarded as an extremely effective method to analyze the interactive behavior of cooperation and competition. So, we can see that evolutionary game model is a reliable approach to track the dynamic and interactive behavior of BIM adopts strategies selection in EPC projects.

The strategies and expected payoffs of each player were first identified in this paper. The replicator equations were developed to indicate the growth rate of the proportion of participants by using a certain strategy. Secondly, we identify the evolutionarily stable states by analyzing the stable fixed points of the equations. Then, the sensitivity of the variable parameters was analyzed by numerical simulation. On the basis of analyzing the influence of the parameters on the evolution path, it provides the basis for the formulation of the strategy.

\section{Evolutionary Game Model Analysis}

\subsection{Assumptions and Payoff Matrix}

Assumption 1. In EPC projects, the owners and general contractors who are the players of the game pursue economic profit maximization [25], and they only have limited rationality. Thus, they need to adjust and improve in the game process to find better strategies through constant trial.

Assumption 2. The owners would choose "promotion" or "nonpromotion" when the owners and contractors conduct the BIM application in EPC projects. The probability that owners choose "promotion" is $x$, and the probability that owners choose "nonpromotion" is $1-x \quad x \in(0,1)$. If owners opt to "promotion," the application of BIM objectives, implementation plans, punishments, and rewards are clearly specified in the project contract. In addition, the owners actively cooperate with the general contractors and perform the functions of supervision, checkout, and evaluation during construction. On the other hand, if the owners who choose "nonpromotion," they neither explicitly stipulate BIM application in the engineering contract nor supervise BIM application during the construction process.

Assumption 3. The action set that the general contractors can choose from when carrying out construction is (adoption, nonadoption). The probability that general contractors choose "adoption" is $y$, and the probability that general contractors choose "nonadoption" is $1-y$ $y \in(0,1)$. If general contractors opt to "adoption," they should explore the application value of BIM and its integrated application function with emerging technologies. Namely, general contractors pay an extra cost for promoting BIM because of the input of materials and human resources. 
The selection of the "nonadoption" strategy means that BIM is not applied or its application scope and depth are limited in the process of construction.

Assumption 4. We set some variables to study the benefits and losses of the owners and general contractors under different strategic combinations. The description of the relevant parameters is shown in Table 1.
Based on the above assumptions and parameter settings, the game payment matrix when the owners and the general contractors choose different strategies can be obtained, as shown in Table 2.

\subsection{Replicator Dynamic System.}

$$
\begin{aligned}
E_{1 x} & =y\left(R_{1}+\Delta R_{1}-C_{1}-S\right)+(1-y)\left(R_{1}+r_{1}-C_{1}+\alpha p D\right), \\
E_{2 x} & =y\left(R_{1}+m r_{2}\right)+(1-y) R_{1}, \\
\overline{E_{x}} & =x E_{1 x}+(1-x) E_{2 x} \\
E_{1 y} & =x\left(R_{2}+\Delta R_{2}-C_{2}+S\right)+(1-x)\left(R_{2}+r_{2}-C_{2}\right), \\
E_{2 y} & =x\left(R_{2}+n r_{1}-C_{3}-\alpha p D\right)+(1-x) R_{2}, \\
\overline{E_{y}} & =y E_{1 y}+(1-y) E_{2 y}
\end{aligned}
$$

where $E_{1 x}, E_{2 x}, E_{1 y}, E_{2 y}$ are the expected payoffs of the owners and general contractors, respectively, choosing the strategies of "promotion," "nonpromotion," "adoption," and "nonadoption." Their average expected payoffs are $\overline{E_{x}}$ and $\overline{E_{y}}$. According to the replicator dynamics introduced by Taylor and Jonker [35], the replication dynamics equation of the owners and general contractors are as follows:

$$
\begin{aligned}
F(x)= & \frac{\mathrm{d} x}{\mathrm{~d} t} \\
= & x\left(E_{1 x}-\overline{E_{x}}\right) \\
= & x(1-x)\left[\left(\Delta R_{1}-r_{1}-m r_{2}-S-\alpha p D\right) y\right. \\
& \left.+\left(r_{1}-C_{1}+\alpha p D\right)\right], \\
F(y)= & \frac{\mathrm{d} y}{\mathrm{~d} t} \\
= & y\left(E_{1 y}-\overline{E_{y}}\right) \\
= & y(1-y)\left[\left(\Delta R_{2}-r_{2}-n r_{1}+C_{3}+S+\alpha p D\right) x\right. \\
& \left.+\left(r_{2}-C_{2}\right)\right] .
\end{aligned}
$$

4.3. Analysis Model. When the dynamic equations (2) and (3) are equal to 0 , four pure strategies equilibrium points, namely, $A(0,0), B(1,0), C(0,1)$, and $D(1,1)$ and mixed strategy equilibrium point $E\left(x^{*}, y^{*}\right)$ can work out, where $x^{*}=C_{2}-r_{2} / \Delta R_{2}-r_{2}-n r_{1}+C_{3}+S+\alpha p D$, $y^{*}=-r_{1}+C_{1}-\alpha p D / \Delta R_{1}-r_{1}-m r_{2}-S-\alpha p D$.

To identify the ESS, the stability of these equilibrium points needs to be analyzed. According to Friedman [36], the Jacobian matrix is applicable to evaluate the evolution equilibrium stability. The Jacobian matrix is given by

$$
\begin{aligned}
J & =\left[\begin{array}{ll}
\frac{\partial F(x)}{\partial x} & \frac{\partial F(x)}{\partial y} \\
\frac{\partial F(y)}{\partial x} & \frac{\partial F(y)}{\partial y}
\end{array}\right] \\
& =\left[\begin{array}{ll}
a_{11} & a_{12} \\
a_{21} & a_{22}
\end{array}\right],
\end{aligned}
$$

where

$$
\begin{aligned}
a_{11}= & (1-2 x)\left[\left(\Delta R_{1}-r_{1}-m r_{2}-S-\alpha p D\right) y\right. \\
& \left.+\left(r_{1}-C_{1}+\alpha p D\right)\right], \\
a_{12}= & x(1-x)\left(\Delta R_{1}-r_{1}-m r_{2}-S-\alpha p D\right), \\
a_{21}= & y(1-y)\left(\Delta R_{2}-r_{2}-n r_{1}+C_{3}+S+\alpha p D\right), \\
a_{22}= & (1-2 y)\left[\left(\Delta R_{2}-r_{2}-n r_{1}+C_{3}+S+\alpha p D\right) x\right. \\
& \left.+\left(r_{2}-C_{2}\right)\right] .
\end{aligned}
$$

The determinant of the Jacobian matrix is $\operatorname{det} J=a_{11} a_{22}-a_{12} a_{21}$, and the trace of the Jacobian matrix is $\operatorname{tr} J=a_{11}+a_{22}$. Then, we can compute the determinant and trace of equilibrium points that are shown in Table 3.

\section{Model Results}

According to evolutionary game theory, when the equilibrium point satisfies $\operatorname{det} J>0$ and $t r J<0$, this equilibrium point is an ESS. Based on parameter settings $\Delta R_{2}-n r_{1}-C_{2}+C_{3}+S+\alpha p D>0$, namely, the extraneous income obtained by general contractors is always positive under the circumstance of the collaborative application of BIM by both parties. With the analysis above, the evolution of the system could be divided into the following scenarios, as shown in Table 4.

Scenario 1: if $r_{1}-C_{1}+\alpha p D>0, r_{2}-C_{2}>0, \Delta R_{1}-m$ $r_{2}-C_{1}-S>0$ and $\Delta R_{2}-n r_{1}-C_{2}+C_{3}+S+\alpha p D>0$. 
TABLE 1: Variable settings and interpretations.

\begin{tabular}{|c|c|}
\hline Game players & Variable settings and interpretations \\
\hline Owners & $\begin{array}{l}R_{1} \text { : EPC project revenues when owners do not promote BIM, } R_{1}>0 \\
\Delta R_{1} \text { : incremental benefits obtained by owners when owners and general contractors collaborative application of BIM, } \\
\qquad \Delta R_{1}>0 \\
r_{1} \text { : incremental incomes generated by the owners taking positive actions alone (the general contractors do not adopt } \\
\qquad C_{1} \text { : the cost paid by owners to promote BIM, } r_{1}>0 \\
p \text { : the probability that owners find that general contractors do not adopt BIM in depth, } 0<p<1 \\
m \text { : the influence coefficient on the interests of the owners when only general contractors take active actions (spillover } \\
\text { coefficient), } 0<m<1\end{array}$ \\
\hline $\begin{array}{l}\text { General } \\
\text { contractors }\end{array}$ & $\begin{array}{l}R_{2} \text { : EPC project revenues when general contractors do not adopt BIM, } R_{2}>0 \\
\Delta R_{2} \text { : incremental benefits obtained by general contractors when owners and general contractors collaborative } \\
\text { application of BIM, } \Delta R_{2}>0 \\
r_{2} \text { : incremental benefits generated by the general contractors taking positive actions alone (the owners do not } \\
\text { promote), } r_{2}>0 \\
\qquad C_{2} \text { : BIM application cost of general contractors, } C_{2}>0 \\
C_{3} \text { : costs paid by general contractors to respond to inspections and assessments when application of BIM is } \\
\text { insufficient, } 0<C_{3}<C_{2} \\
\qquad \text { : the performance bond paid by the general contractors according to the contract, } D>0 \\
\begin{array}{r}\alpha \text { : the percentage of deduction of performance bond when general contractors fail to adopt BIM in accordance with the } \\
\text { contract } 0<\alpha<1\end{array} \\
\qquad \text { : rewards for general contractors actively adopting BIM, } S>0 \\
\text { coefficient), } 0<n<1\end{array}$ \\
\hline tantide & $\begin{array}{l}\text { Spillover effect: when an organization takes measure, it will not only produce the expected result, but also have an impact on th } \\
\text { zation. For example, when one party adopts BIM, it can provide convenience for other participants to share information and wor } \\
\text { al contractors shorten the project cycle through BIM application, and the owners also benefit from it. We use " } m, n \text { " to express th }\end{array}$ \\
\hline
\end{tabular}

TABLE 2: Game payoff matrix.

\begin{tabular}{cccc}
\hline & Game players & General contractors & Nonadoption $(1-y)$ \\
\hline \multirow{3}{*}{ Owners } & Promotion $(x)$ & Owners: $R_{1}+\Delta R_{1}-C_{1}-S$, & Owners: $R_{1}+r_{1}-C_{1}+\alpha p D$, \\
& Nonpromotion $(1-x)$ & General contractors: $R_{2}+\Delta R_{2}-C_{2}+S$ & General contractors: $R_{2}+n r_{1}-C_{3}-\alpha p D$ \\
& Owners: $R_{1}+m r_{2}$, & Owners: $R_{1}$, \\
& General contractors: $R_{2}+r_{2}-C_{2}$ & General contractors: $R_{2}$ \\
\hline
\end{tabular}

TABLE 3: The determinant and trace at each equilibrium point.

\begin{tabular}{lcc}
\hline $\begin{array}{l}\text { Equilibrium } \\
\text { points }\end{array}$ & Equation of det $J$ & Equation of trJ \\
\hline$A(0,0)$ & $\left(r_{1}-C_{1}+\alpha p D\right)\left(r_{2}-C_{2}\right)$ & $\left(r_{1}-C_{1}+\alpha p D\right)+\left(r_{2}-C_{2}\right)$ \\
$B(1,0)$ & $-\left(r_{1}-C_{1}+\alpha p D\right)\left(\Delta R_{2}-n r_{1}-C_{2}+C_{3}+S+\alpha p D\right)$ & $-\left(r_{1}-C_{1}+\alpha p D\right)+\left(\Delta R_{2}-n r_{1}-C_{2}+C_{3}+S+\alpha p D\right)$ \\
$C(0,1)$ & $-\left(\Delta R_{1}-m r_{2}-C_{1}-S\right)\left(r_{2}-C_{2}\right)$ & $-\left(r_{2}-C_{2}\right)+\left(\Delta R_{1}-m r_{2}-C_{1}-S\right)$ \\
$D(1,1)$ & $\left(\Delta R_{1}-m r_{2}-C_{1}-S\right)\left(\Delta R_{2}-n r_{1}-C_{2}+C_{3}+S+\alpha p D\right)$ & $-\left(\Delta R_{1}-m r_{2}-C_{1}-S\right)-\left(\Delta R_{2}-n r_{1}-C_{2}+C_{3}+S+\alpha p D\right)$ \\
$E\left(x^{*}, y^{*}\right)$ & $\mu$ & 0 \\
\hline$\mu\left(r_{2}-C_{2}\right)\left(r_{1}-C_{1}+\alpha p D\right)\left(\Delta R_{1}-m r_{2}-C_{1}-S\right)\left(\Delta R_{2}-n r_{1}-C_{2}+C_{3}+S+\alpha p D\right) /\left(-\left(\Delta R_{1}-r_{1}-m r_{2}-S-\alpha p D\right)\left(\Delta R_{2}-r_{2}-n r_{1}+C_{3}+S+\alpha p D\right)\right)$.
\end{tabular}

Thus, the ESS is $(1,1)$. Regardless of whether the owners implement BIM incentives or not, general contractors will choose to adopt BIM in EPC projects. And for owners, no matter how the general contractors choose, the owners will promote BIM. The two parties can obtain incremental benefits when owners and general contractors adopt BIM collaboratively in EPC projects, and the additional benefits gained by itself can offset the costs paid when only one party takes active measures, so two players' dominant strategies are independent in this scenario.

Scenario 2: if $r_{1}-C_{1}+\alpha p D<0, r_{2}-C_{2}>0, \Delta R_{1}$ $-m r_{2}-C_{1}-S>0$, and $\Delta R_{2}-n r_{1}-C_{2}+C_{3}+S+\alpha p D>0$, then the ESS is $(1,1)$. This scenario indicates that regardless of whether owners promote or not, general contractors' 
TABLE 4: The evolutionary stabilization strategy of the system.

\begin{tabular}{|c|c|c|c|c|c|c|}
\hline & \multirow{2}{*}{ Scenario } & & \multicolumn{4}{|c|}{ Equilibrium $(x, y)$} \\
\hline & & & $A(0,0)$ & $B(1,0)$ & $C(0,1)$ & $D(1,1)$ \\
\hline \multirow{4}{*}{ Scenario 1} & $r_{1}-C_{1}+\alpha p D>0$ & $\operatorname{det} J$ & + & - & - & + \\
\hline & $r_{2}-C_{2}>0$ & $\operatorname{trJ}$ & + & Unknown & Unknown & - \\
\hline & $\Delta R_{1}-m r_{2}-C_{1}-S>0$ & Stable & Unstable & Unstable & Unstable & ESS \\
\hline & $r_{1}-C_{1}+\alpha p D<0$ & $\operatorname{det} J$ & - & + & - & + \\
\hline \multirow[t]{2}{*}{ Scenario 2} & $r_{2}-C_{2}>0$ & $\operatorname{trJ}$ & Unknown & + & Unknown & - \\
\hline & $\Delta R_{1}-m r_{2}-C_{1}-S>0$ & Stable & Unstable & Unstable & Unstable & ESS \\
\hline \multirow{3}{*}{ Scenario 3} & $r_{1}-C_{1}+\alpha p D>0$ & $\operatorname{det} J$ & - & - & + & + \\
\hline & $r_{2}-C_{2}<0$ & $\operatorname{trJ}$ & Unknown & Unknown & + & - \\
\hline & $\Delta R_{1}-m r_{2}-C_{1}-S>0$ & Stable & Unstable & Unstable & Unstable & ESS \\
\hline \multirow{3}{*}{ Scenario 4} & $r_{1}-C_{1}+\alpha p D>0$ & $\operatorname{det} J$ & + & - & + & - \\
\hline & $r_{2}-C_{2}>0$ & $\operatorname{trJ}$ & + & Unknown & - & Unknown \\
\hline & $\Delta R_{1}-m r_{2}-C_{1}-S<0$ & Stable & Unstable & Unstable & ESS & Unstable \\
\hline \multirow{3}{*}{ Scenario 5} & $r_{1}-C_{1}+\alpha p D<0$ & de $t J$ & - & + & + & - \\
\hline & $r_{2}-C_{2}>0$ & $\operatorname{trJ}$ & Unknown & + & - & Unknown \\
\hline & $\Delta R_{1}-m r_{2}-C_{1}-S<0$ & Stable & Unstable & Unstable & ESS & Unstable \\
\hline \multirow{3}{*}{ Scenario 6} & $r_{1}-C_{1}+\alpha p D<0$ & $\operatorname{det} J$ & + & + & + & + \\
\hline & $r_{2}-C_{2}<0$ & $\operatorname{trJ}$ & - & + & + & - \\
\hline & $\Delta R_{1}-m r_{2}-C_{1}-S>0$ & Stable & ESS & Unstable & Unstable & ESS \\
\hline \multirow{3}{*}{ Scenario 7} & $r_{1}-C_{1}+\alpha p D>0$ & $\operatorname{det} J$ & - & - & - & - \\
\hline & $r_{2}-C_{2}<0$ & $\operatorname{trJ}$ & Unknown & Unknown & Unknown & Unknown \\
\hline & $\Delta R_{1}-m r_{2}-C_{1}-S<0$ & Stable & Unstable & Unstable & Unstable & Unstable \\
\hline \multirow{3}{*}{ Scenario 8} & $r_{1}-C_{1}+\alpha p D<0$ & $\operatorname{det} J$ & + & + & - & - \\
\hline & $r_{2}-C_{2}<0$ & $\operatorname{trJ}$ & - & + & Unknown & Unknown \\
\hline & $\Delta R_{1}-m r_{2}-C_{1}-S<0$ & Stable & ESS & Unstable & Unstable & Unstable \\
\hline
\end{tabular}

dominant strategy is to go for BIM in EPC projects because incremental income can cover its extra cost. The incentives are unimportant for general contractors, but when owners provide high level incentives, the benefits are eventually absorbed by owners with positive externality.

Scenario 3: if $r_{1}-C_{1}+\alpha p D>0, r_{2}-C_{2}<0, \Delta R_{1}-$ $m r_{2}-C_{1}-S>0$, and $\Delta R_{2}-n r_{1}-C_{2}+C_{3}+S+\alpha p D>0$, then the ESS is $(1,1)$. In EPC projects, the benefits cannot cover its extra costs when the general contractors take positive measures unilaterally. However, the general contractors' incremental benefits can be positive due to the owners' rewards when both parties collaborate to adopt BIM. In this scenario, if owners provide incentives, then general contractors can benefit from going for BIM. Otherwise, they tend not to adopt BIM. For the owners, regardless of whether the general contractors adopt BIM or not, they can benefit from incentive measures, so they prefer to implement incentives. In this sense, general contractors' dominant strategies depend on owner' choices, indicating that the incentive level in this scenario is attractive to general contractors and owners can afford.

Scenario 4: if $r_{1}-C_{1}+\alpha p D>0, r_{2}-C_{2}>0, \Delta R_{1}-$ $m r_{2}-C_{1}-S<0$, and $\Delta R_{2}-n r_{1}-C_{2}+C_{3}+S+\alpha p D>0$, regardless of whether owners implement BIM incentives or not, doing BIM is always profitable for general contractors. Therefore, the proportion of general contractors constructing BIM gradually increases to 1 . On the other hand, owners who adopt incentive strategies can maintain positive earnings after receiving fines from the general contractors, but they cannot afford high subsidies. And the proportion of owners implement incentives gradually increases to 0 . Thus, the ESS is $B(0,1)$. In this sense, owners' dominant strategies depend on general contractors' choices. The general contractors adopt BIM should have a high incremental benefit, which can at least cover the additional costs, so as not to dependent on the owner's financial incentive.

Scenario 5: if $r_{1}-C_{1}+\alpha p D<0 \quad$ and $\Delta R_{1}-m r_{2}-C_{1}-S<0$, it indicates no matter what the general contractors' strategy is, the incremental revenue of the owners' incentive strategy is negative, so they choose "not promote" strategy. Simultaneously, $r_{2}-C_{2}>0$ and $\Delta R_{2}-n r_{1}-C_{2}+C_{3}+S+\alpha p D>0$, whether the owners promote BIM or not, the cost of BIM application by the general contractor in EPC project is less than the incremental benefit, so the general contractors choose to actively adopt BIM in the project. Then the ESS is $(0,1)$.

Scenario 6: if $\quad r_{1}-C_{1}+\alpha p D<0, r_{2}-$ $C_{2}<0, \Delta R_{1}-m r_{2}-C_{1}-S>0, \quad$ and $\quad \Delta R_{2}-n r_{1}-C_{2}+$ $C_{3}+S+\alpha p D>0$, then the ESSs are $(0,0)$ and $(1,1)$ in this scenario. Since attainment of ESS depends on the beginning positions of the two players, illustrated by the numerical simulation of in Figure 1(b), the ESS is $(1,1)$ when $x_{0}=0.6, y_{0}=0.3$, and the ESS is $(0,0)$ when $x_{0}=0.4, y_{0}=0.2$. And as we can see from Figure $1(\mathrm{a})$, the dotted line divides the graph into four areas. When the initial strategies of owners and general contractors are located in the upper right two areas, the system evolves to $(1,1)$. If most general contractors tend not to adopt BIM at the beginning, and owners tend to implement incentives, then the proportion of general contractors doing BIM can increase to 1 . When the initial strategies of the two are located in the lower left two areas, the evolutionary game of the two sides evolves 


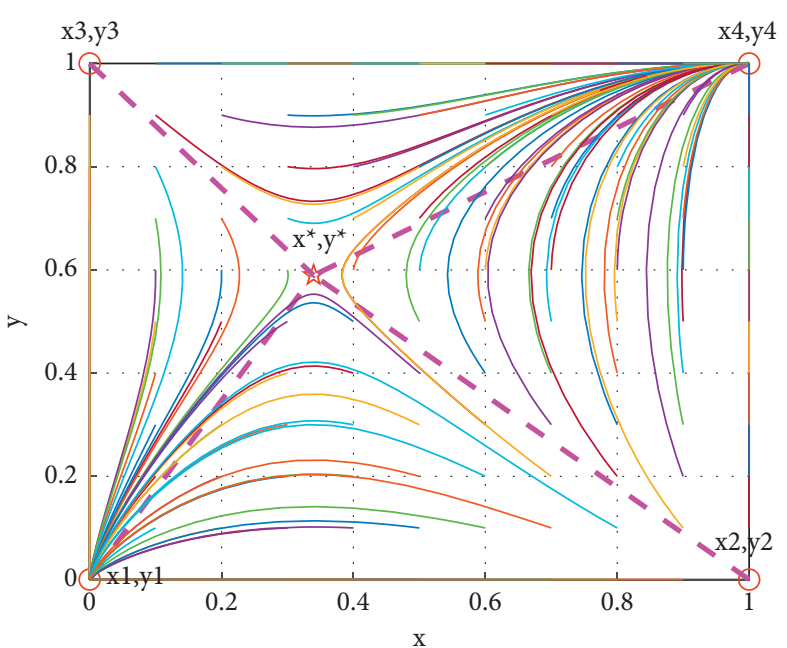

(a)

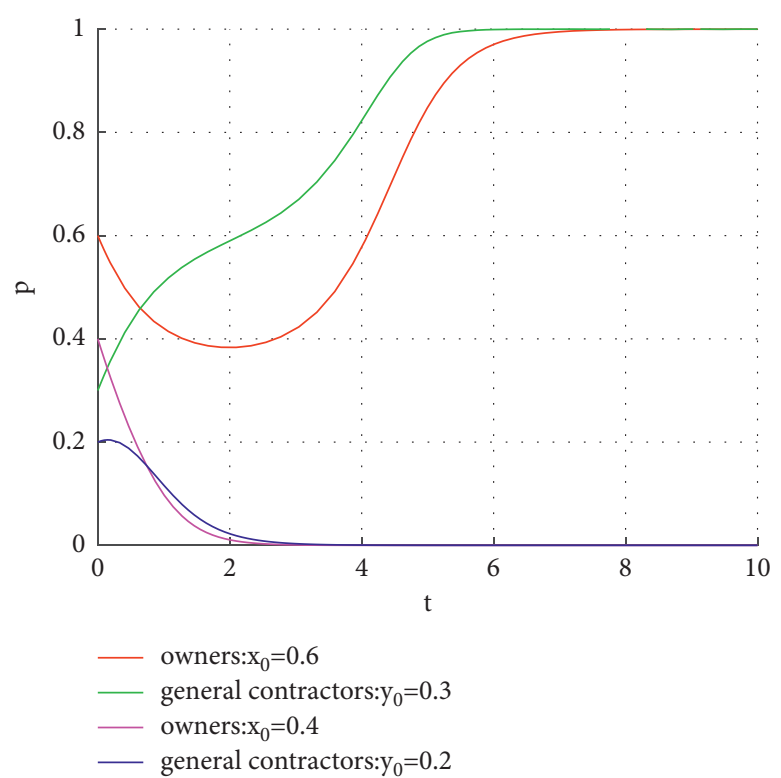

(b)

Figure 1: Dynamic evolution in Scenario 6. (a) Evolution path. (b) Evolution with different initial strategies.

to $(0,0)$. If most general contractors prefer to do BIM, and owners tend not to provide incentives, then the proportion of general contractors constructing BIM can decrease to 0 . In this scenario, when both parties individually take positive actions, the benefits cannot cover costs, while the excess benefits obtained by both parties in the collaborative application of BIM are higher than the cost. Whether general contractors construct BIM depends on whether owners provide incentives and vice versa.

Scenario 7: if $r_{1}-C_{1}+\alpha p D>0, r_{2}-C_{2}<0, \Delta R_{1}-m r_{2}$ $-C_{1}-S<0$, and $\Delta R_{2}-n r_{1}-C_{2}+C_{3}+S+\alpha p D>0$, this scenario is the case when the high price premium of BIM cannot offset its extra cost, but owners' incentives can help cover the costs. The general contractors' application of BIM depends on the existence of BIM incentives. As shown in Figure 2(a), there is no ESS. The incentives measure is necessary, and their level must be attractive to general contractors, but it burdens owners in terms of implementing incentives and thus the incentive is unsustainable. In this scenario, the proportion of general contractors going for BIM will increase gradually with incentives. As a result, owners tend to remove the incentives to maximize their profits. If owners do so, then general contractors can change their strategies and choose not to apply BIM. Thus, the proportion of general contractors going for BIM can decrease gradually. Consequently, owners can change their strategy and tend to promote BIM incentives to improve profits. Therefore, the system can never become stable in EPC projects. The evolution paths are cyclical and can never reach stable points when $x_{0}=0.6, y_{0}=0.3$, as illustrated in Figure 2(b). Essentially, the choice of one player depends on that of the opposite player.
Scenario 8: if $r_{1}-C_{1}+\alpha p D<0, r_{2}-C_{2}<0, \Delta R_{1}-$ $m r_{2}-C_{1}-S<0$, and $\Delta R_{2}-n r_{1}-C_{2}+C_{3}+S+\alpha p D>0$, in the EPC project, general contractors adopt BIM to obtain negative benefits when the owners do not promote BIM, and the incentives of both parties to cooperate with the BIM owners can make up for the loss of general contractors. Therefore, whether general contractors construct BIM depends on whether owners provide incentives. The incentive is important and attractive to general contractors but unaffordable to owners. Thus, the ESS is $(0,0)$.

\section{Numerical Simulation and Discussion}

It can be seen that the evolutionary stability strategy of Scenario 6 might be a cooperation strategy between the owners and general contractors according to the abovementioned analysis. To increase the probability of cooperation between both sides and realize the synergistic benefits of BIM applications, Scenario 6 of the original model and extended model is chosen for simulation in the evolutionary game model. According to the regulations on contract bonds in projects, the profitability of enterprises applying BIM technology is present as well as the principle of equation balance, and the initial parameters are set to $\Delta$ $R_{1}=10, \Delta R_{2}=8, r_{1}=1, r_{2}=2, C_{1}=6, C_{2}=4, C_{3}=1, S$ $=2, D=10, p=0.8, \alpha=0.5, m=0.6, n=0.5$. During the process of analyzing the influence of each parameter on the system evolution, we only change the parameters that need to be analyzed, and the rest of the parameter values remain unchanged.

The strategies adopted by both parties for the collaborative application of BIM are directly affected by the initial strategies and variable parameters in the EPC project. The following is 


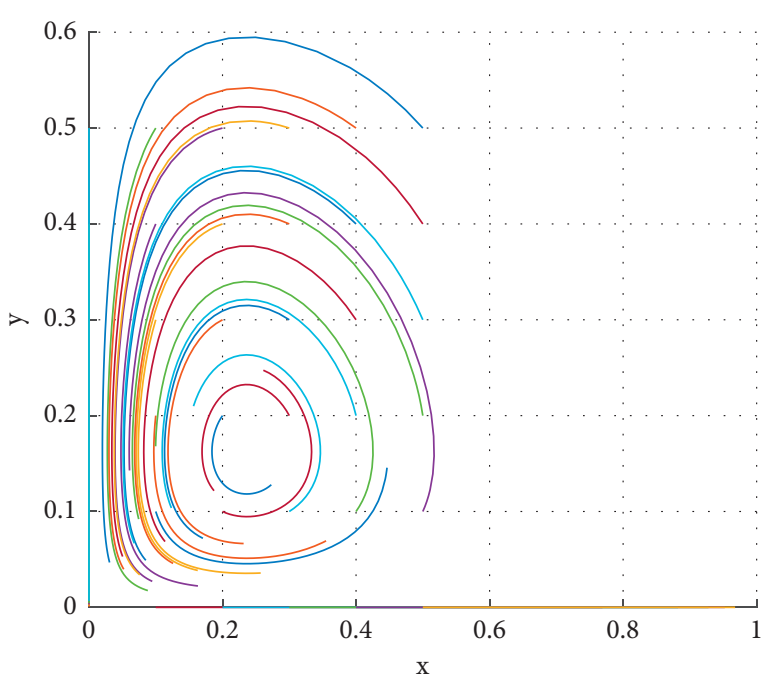

(a)

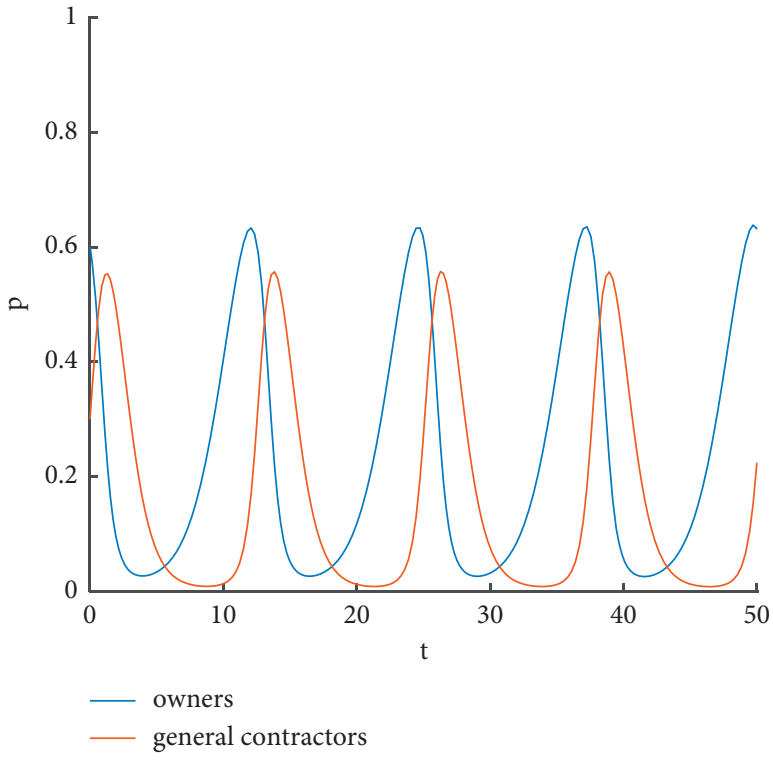

(b)

Figure 2: Dynamic evolution in Scenario 7. (a) Evolution path. (b) Evolution with $x_{0}=0.6, y_{0}=0.3$.

an evolutionary game numerical simulation of the initial willingness and sensitivity analysis of the variable parameters.

6.1. Impact of Different Initial Strategies. We may suppose that different initial strategies could influence the results of the evolutionary game model in Scenario 6. As depicted in Figures 3(a) and 3(b), we can draw a conclusion that when $y_{0}$ is fixed, the system changes from noncooperation to cooperation with an increasing $x_{0}$. Correspondingly, the system changes in the same manner when $x_{0}$ is fixed (as shown in Figures 3(c) and $3(d))$. The strategy choice of the owners and general contractors is path-dependent and the convergence speed of the system evolution is related to the selection of the initial proportion of behavior. In the initial strategies, the more owners choose to promote and general contractors choose to adopt BIM, the easier it is to obtain an ideal situation in EPC projects.

6.2. Sensitivity Analysis of Different Parameters. In the evolutionary game process of the collaborative application of BIM, various parameters may change the ESS in Scenario 6. To reveal the impacts of these parameters on the results, we conduct a sensitivity analysis using different parameters in this part. The construction companies, especially small- and medium-sized firms, are less willing to adopt BIM at present $[37,38]$, and the status of the owners is often higher than that of construction side in the process of engineering construction. Hence, the following focuses on analyzing the influence of different parameters on the system evolution under the circumstance of $y_{0}=0.3$. And on this basis, the measures to promote the collaborative application of BIM between the two parties in the EPC project are put forward. Take the initial value of each parameter and draw the comparison diagram on sensitivity analysis of equilibrium points (see Figure 4).

6.2.1. Impact of BIM Incremental Revenue. Figures 4 and 5 show that the whole system transitions to the state of (promotion, adoption) with the increase of incremental revenue in the collaborative application of BIM technology between owners and general contractors, which is conducive to cooperation between the two parties in the construction project. By comparing Figures 4 and 5, when the incremental gains $\Delta R_{1}$ and $\Delta R_{2}$ change by $30 \%$ at the same time, the system evolution state of owners changes more rapidly, so the owners' promotion could promote cooperation to evolve in the desired direction more quickly.

6.2.2. Impact of BIM Costs. By comparing Figures 4 and 6, we can see that owners and general contractors change to a state of "noncooperation" due to increased costs, so controlling BIM application costs plays an important role in promoting the probability of cooperation. When the cost of both sides changes by $20 \%$, the change of the owners' cost is more sensitive to the evolution of the system. If the general contractors' BIM application cost $\left(C_{2}\right)$ increases, the difference between coping with inspection costs $\left(C_{3}\right)$ goes up. Coping with inspection costs $\left(C_{3}\right)$ is negatively correlated with the general contractors' ability to adopt BIM. When owners encourage application of BIM and strengthen assessment during the construction process, general contractors need to pay higher costs. Then, general contractors will turn to the application of BIM technology strategies to realize the collaborative application of both parties. 


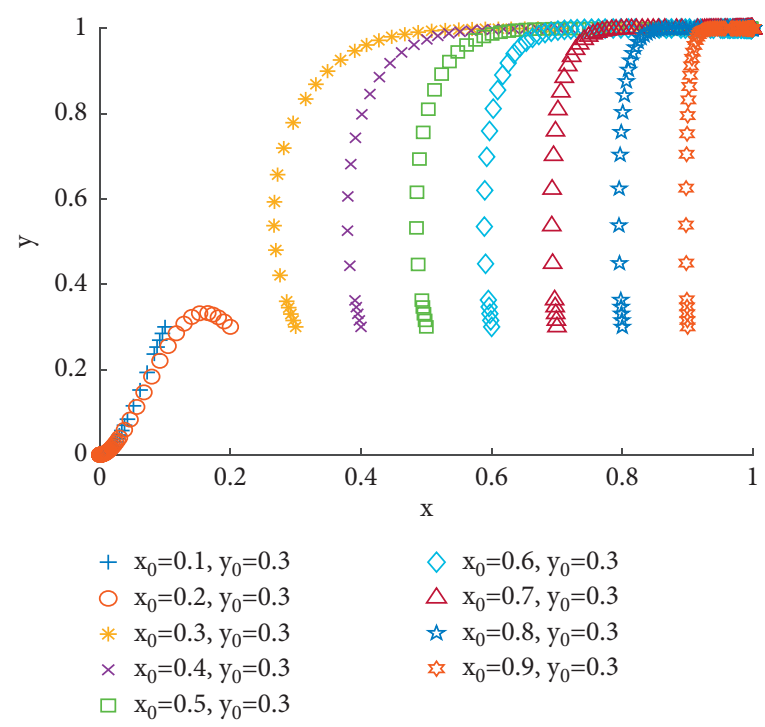

(a)

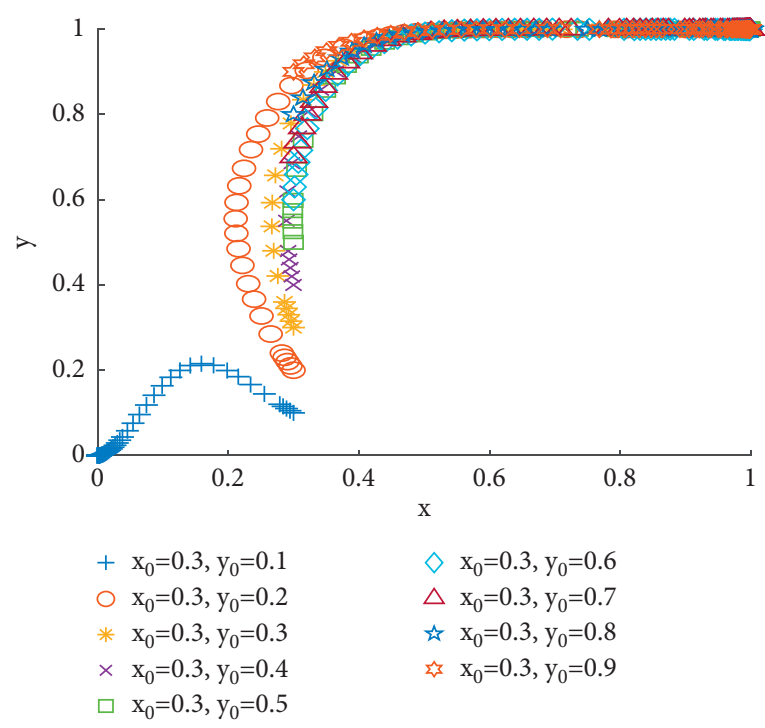

(c)

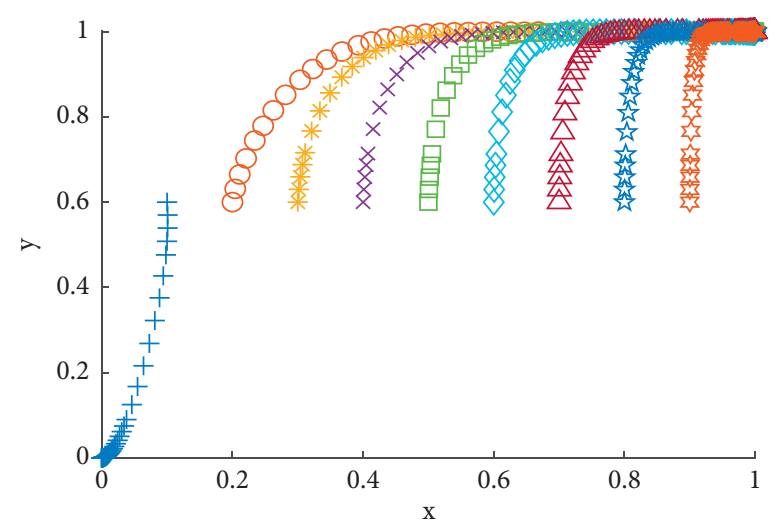

$+\mathrm{x}_{0}=0.1, \mathrm{y}_{0}=0.6$
$\odot \mathrm{x}_{0}=0.2, \mathrm{y}_{0}=0.6$
$+\mathrm{x}_{0}=0.3, \mathrm{y}_{0}=0.6$
$\times \mathrm{x}_{0}=0.4, \mathrm{y}_{0}=0.6$
$\square \mathrm{x}_{0}=0.5, \mathrm{y}_{0}=0.6$

$\diamond \mathrm{x}_{0}=0.6, \mathrm{y}_{0}=0.6$

$\triangle \mathrm{x}_{0}=0.7, \mathrm{y}_{0}=0.6$

is $\mathrm{x}_{0}=0.8, \mathrm{y}_{0}=0.6$

\& $\mathrm{x}_{0}=0.9, \mathrm{y}_{0}=0.6$

(b)

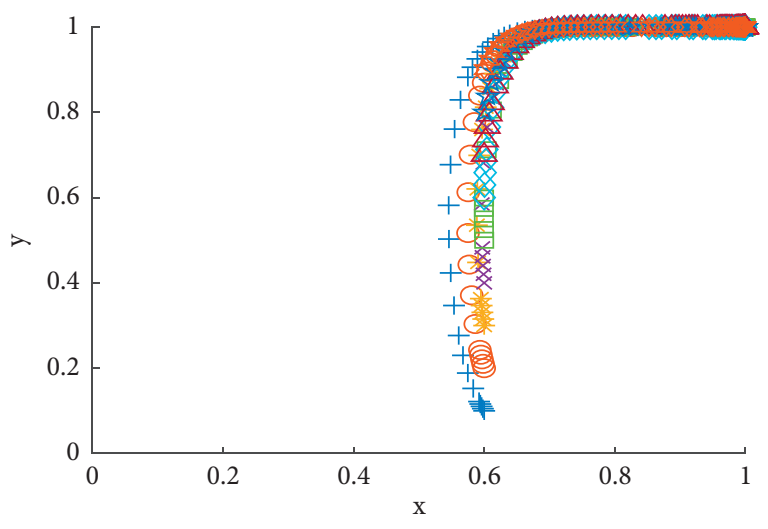

$+\mathrm{x}_{0}=0.6, \mathrm{y}_{0}=0.1$
$\odot \mathrm{x}_{0}=0.6, \mathrm{y}_{0}=0.2$
$* \mathrm{x}_{0}=0.6, \mathrm{y}_{0}=0.3$
$\times \mathrm{x}_{0}=0.6, \mathrm{y}_{0}=0.4$
$\square \mathrm{x}_{0}=0.6, \mathrm{y}_{0}=0.5$

$\diamond \mathrm{x}_{0}=0.6, \mathrm{y}_{0}=0.6$

$\triangle \mathrm{x}_{0}=0.6, \mathrm{y}_{0}=0.7$

मे $\mathrm{x}_{0}=0.6, \mathrm{y}_{0}=0.8$

$\Leftrightarrow \mathrm{x}_{0}=0.6, \mathrm{y}_{0}=0.9$

(d)

FIGURE 3: Diagram on the impact of different initial strategies. (a) $y_{0}=0.3$, (b) $y_{0}=0.6$, (c) $x_{0}=0.3$, and (d) $x_{0}=0.6$.

6.2.3. Impact of the Revenue Spillover Coefficient. By comparing Figures 4 and 7, it can be found the system evolves into a state of "noncooperation" with the increase of revenue spillover coefficient, namely, the owners and general contractors in the EPC project no longer actively adopt BIM. It can be seen from Figure 7 that the curve changes more obviously when the spillover effect coefficient $m$ changes. It suggests that the owners can obtain greater project profits due to external effects compared with the general contractors. Because the application of BIM enables the building to obtain better performance and lays a solid foundation for operation and maintenance management. There will be a "hitchhiking" situation in which the other party takes active actions that result in the negative treatment of both parties. To a certain extent, the spillover index of incremental earnings is beneficial to the promotion of BIM technology, but the degree of understanding is crucial. Therefore, certain regulatory measures are required for bilateral cooperation.

6.2.4. Impact of the Owners' Incentive Measures. The owners need not to intervene if the general contractors are willing to adopt BIM. However, general contractors have to be compelled to pay higher prices to introduce BIM in the early stage. In general, general contractors are unwilling to reform, and owners will certainly need to implement incentives. Three situations were simulated when $x_{0}=0.6$ and $y_{0}=0.3$. The three situations are that the owners do not implement incentives, the owners only reward without punishment, and the owners both reward and punish. The results are presented in Figure 8. 


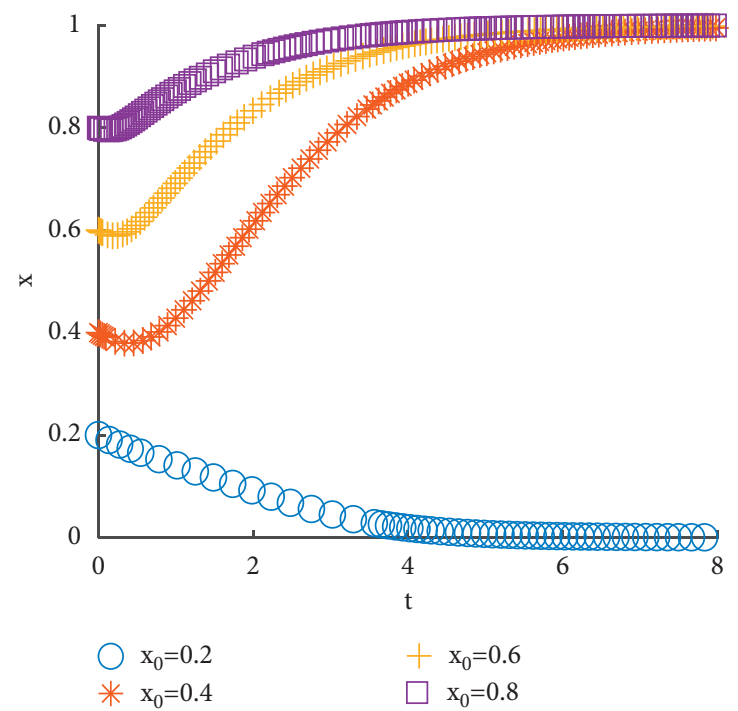

FIgURE 4: The comparison diagram on sensitivity analysis of equilibrium points. Take initial values for all parameters.

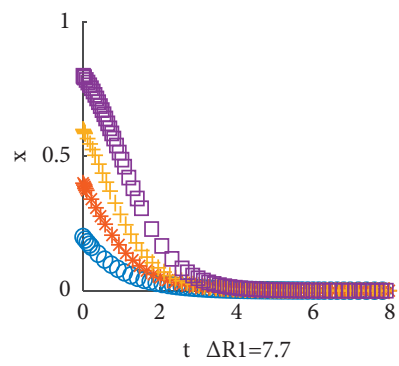

$\begin{array}{ll}\mathrm{x}_{0}=0.2 & +\mathrm{x}_{0}=0.6 \\ * \mathrm{x}_{0}=0.4 & \square \mathrm{x}_{0}=0.8\end{array}$

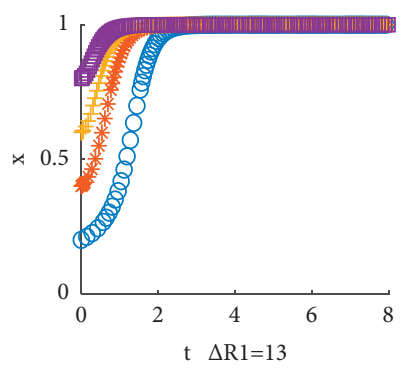

$\mathrm{x}_{0}=0.2+\mathrm{x}_{0}=0.6$

* $\mathrm{x}_{0}=0.4 \quad \square \mathrm{x}_{0}=0.8$

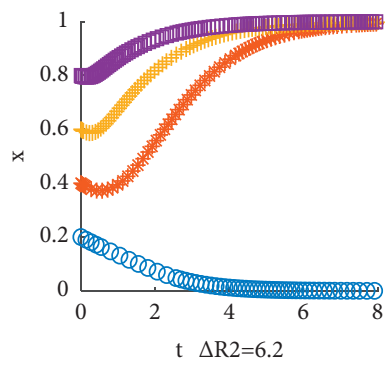

列 $=0.2+\mathrm{x}_{0}=0.6$

* $\mathrm{x}_{0}=0.4 \quad \square \mathrm{x}_{0}=0.8$

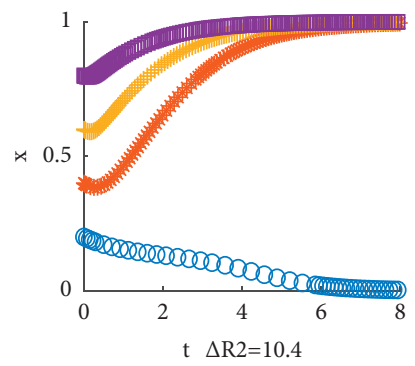

○ $\mathrm{x}_{0}=0.2+\mathrm{x}_{0}=0.6$

* $\mathrm{x}_{0}=0.4 \quad \square \mathrm{x}_{0}=0.8$

FIgURE 5: The impact of BIM incremental revenue on evolution system.

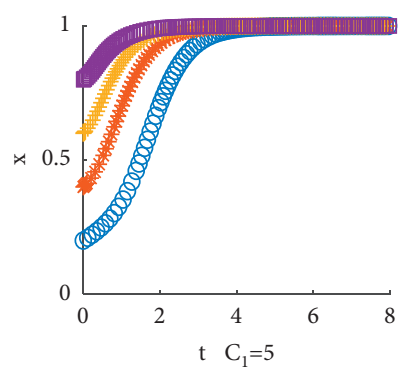

O $\mathrm{x}_{0}=0.2$

* $\mathrm{x}_{0}=0.4$

$+\mathrm{x}_{0}=0.6$

$\square \mathrm{x}_{0}=0.8$

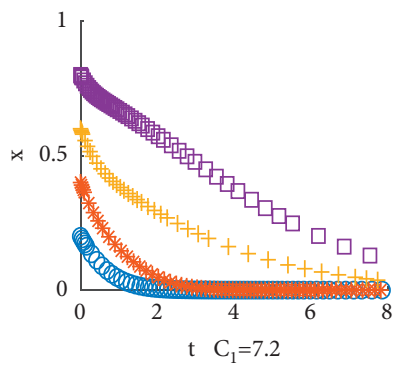

的 $=0.2$

* $\mathrm{x}_{0}=0.4$

$+\mathrm{x}_{0}=0.6$

$\square \mathrm{x}_{0}=0.8$

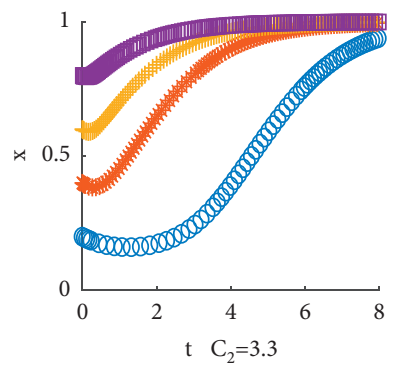

○ $\mathrm{x}_{0}=0.2+\mathrm{x}_{0}=0.6$

* $\mathrm{x}_{0}=0.4 \quad \square \mathrm{x}_{0}=0.8$

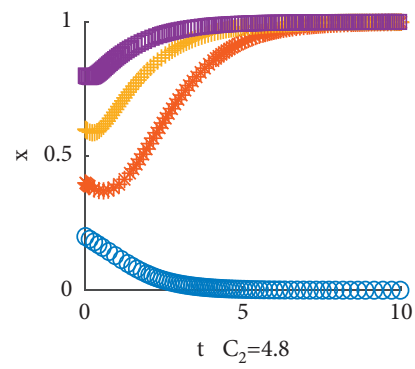

$\mathrm{x}_{0}=0.2+\mathrm{x}_{0}=0.6$

* $\mathrm{x}_{0}=0.4 \quad \square \mathrm{x}_{0}=0.8$

FIgURE 6: The impact of BIM costs on evolution system.

As shown in Figure 8, the owners do not implement incentives, and the general contractors cannot obtain considerable profits in a short period of time when $x_{0}=0.6$, $y_{0}=0.3$. Both parties will gradually evolve into a state of "noncooperation." When the owners reward without punishment, there is little effect when owners pay a high amount of funds, so the owners tend to be reluctant to implement incentives. The general contractors actively adopt BIM because of the subsidy at the start of the period. As owners do not promote BIM, the general contractors will no longer actively explore the value of BIM. When owners both reward and punish, the stable strategy of "bilateral cooperation" will be formed in the sixth phase. Therefore, to encourage general contractors to deeply adopt BIM, owners must make clear 

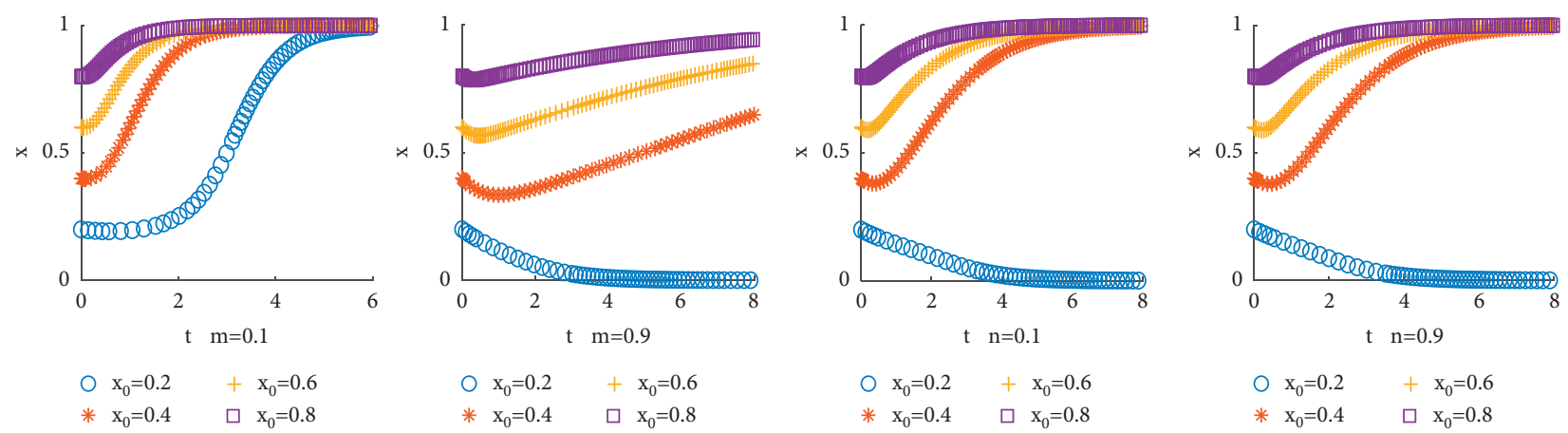

FIgURE 7: The impact of revenue spillover coefficient on evolution system.

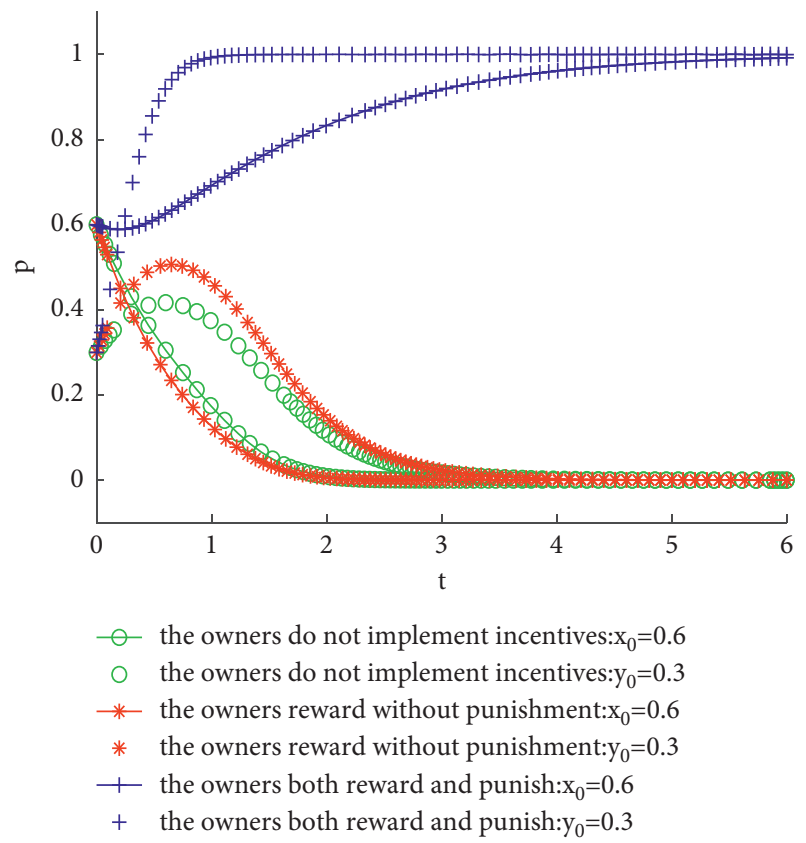

FIgURE 8: The impact of owners' intervention.

regulations on the application of BIM and clarify the system of reward and punishment intensity when signing the contract. However, the amount of reward and punishment must be controlled within a reasonable range; otherwise, they will be counterproductive. For example, when the reward increases to 3 (as shown in Figure 9), there is no longer a tendency to adopt an incentive strategy.

6.3. Solutions. Whether owners and general contractors actively adopt BIM in EPC project is the result of the comprehensive action of many factors. In addition, the strategic choice of one party is affected by the behavioral decision of the other party. In order to promote the development of BIM, it is necessary to proceed from various aspects.

6.3.1. Paying Attention to BIM Application Value in EPC Projects. It can be known that the owners implement incentives can make the system evolve to the ideal state more

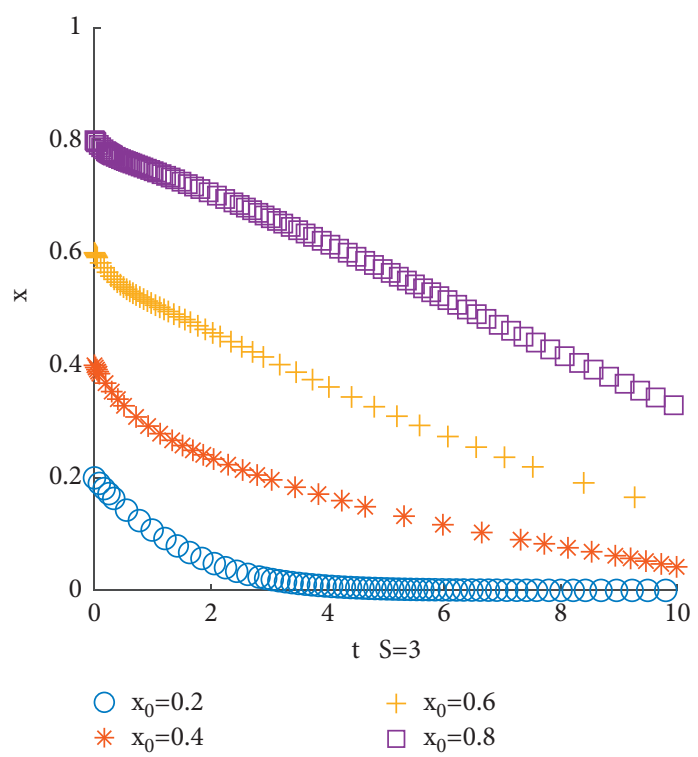

Figure 9: The impact of owners' rewards.

quickly through simulation, so the owners' attitude towards BIM directly affects the general contractors' attention to it. At present, many owners in EPC projects do not have a BIM team, and the customization target at the early stage of the project is too high which is difficult to achieve. It is important for owners to enhance the awareness of BIM application. They can set up a BIM technical review team to supervise the construction process strictly. And they should provide high-quality BIM platform and a strict operating regime to build a good collaboration environment, which can reduce the pressure of general contractors' collaboration cost and carry out efficient life cycle management.

6.3.2. Innovative Application of BIM. The project employees mistakenly assume that the construction of three-dimensional models, input data through collaborative platform, and construction simulation increase the computing efforts. The application level and scope of BIM affect the benefits. As the construction leader of the project, the general contractors should track the project situation in real time and process large amounts of information quickly with the help 
of the BIM collaborative management platform. At the same time, enterprises need to take the initiative to innovate, combined with BIM to attempt other digital technologies in the actual project, thus reducing workload while optimizing costs.

6.3.3. Controlling the Costs of BIM Application. The general contractors invested huge costs due to applying BIM at the start of the project. The huge costs involve software and hardware costs, technical costs, and organizational costs. In view of the EPC project situation, the project team chooses necessary software to purchase and carries out reasonable upgrading of hardware equipment. The general contractors form a corresponding construction BIM team based on the EPC project's scale, professional focus, and contract requirements and strive to be small and precise.

6.3.4. Establishing Stakeholder Responsibility System. The spillover effect coefficient is negatively related to the behavioral strategies of both sides, and unilateral enjoyment of the spillover effect makes the system evolve towards noncooperation. The two parties should establish a stakeholder responsibility system and clearly divide their responsibilities and obligations. Compared with the general contractors, the owners can obtain greater project profits due to external effects. In order to guide the owners to take positive actions and prevent them from blindly "free-riding," the third-party supervision is particularly important at this point.

6.3.5. Creating BIM Collaborative Application Incentive Mechanisms. It is known that the system can evolve to the ideal state quicker if owners reward and punish appropriately through numerical simulation. It is also crucial to design a proper motivation contract for contractors when project owner is willing to use BIM. The contract clarifies the BIM application goal and BIM implementation plan and refines the rules for reward and punishment. In addition, the performance bond submitted by the general contractors can list a separate item for the applying of BIM technology.

\section{Conclusions}

Effective collaboration between owners and general contractors could be valuable in proving the level of BIM application. First, the article focuses on the application of BIM in current EPC projects by conducting a literature review, which is not only restricted by its own funds, technology, and organization structure, but also affected by the attitudes of other participants towards BIM. Second, an evolutionary game model between owners and general contractors was developed to identify the ESSs under different payoffs and strategies. And the evolution path of synergistic behavior and the influence of parameter changes on the evolution of the system were analyzed. The results showed that (1) the initial proportion of the selection strategy affects the evolution direction, speed, and result of the system; (2) the benefits of the collaborative application of BIM are positively correlated with the behavioral strategies of both parties, and the cost of BIM application is negatively correlated with the behavioral strategies of both parties; (3) unilateral enjoyment of the spillover effect would lead each parties to the trial of noncooperation; (4) appropriate reward and penalty system can make the system evolve to the ideal state quicker. Third, five solutions were formulated for effective collaboration between owners and general contractors. These solutions are (1) paying attention to BIM application value in EPC projects, (2) innovative application of BIM, (3) controlling the costs of BIM application, (4) establishing stakeholder responsibility system, and (5) creating BIM collaborative application incentive mechanisms.

The study investigates the dynamic collaboration application of BIM decision-making process between owners and general contractors who are considered as boundedly rational players. The evolutionary game model that proposed provides a theoretical basis for quantitative research on collaboration between owners and general contractors. And it can be used to investigate the collaboration among other related stakeholders. From a practical view, this study provides a valuable reference in promoting the collaboration between owners and general contractors. Practitioners would benefit by understanding the mechanism of the collaboration and by selecting proper strategies to be applied. Despite its advantages, the proposed evolutionary model has two limitations. First, the project participants' recognition of BIM technology was not considered in the model. Second, only the collaboration between owners and general contractors is taken into account due to the limited space of the paper. The general contractors may be a combination of designers and constructors, in which the cooperative game is not taken into consideration. Therefore, future studies should be further refined.

\section{Data Availability}

The data used to support the findings of this study are available from the corresponding author upon request.

\section{Conflicts of Interest}

The authors declare that there are no conflicts of interest regarding the publication of this study.

\section{Acknowledgments}

This work was supported by the National Natural Science Foundation of China (Grant no. 51878026).

\section{References}

[1] X. Zhang, M. Skitmore, and Y. Peng, "Exploring the challenges to industrialized residential building in China," Habitat International, vol. 41, pp. 176-184, 2014.

[2] M. Aldhaheri, A. Bakchan, and M. A. Sandhu, "A structural equation model for enhancing effectiveness of engineering, procurement and construction (EPC) major projects," Engineering Construction and Architectural Management, vol. 25, no. 9, pp. 1226-1252, 2018. 
[3] Y. Yang, W. Tang, W. Shen, and T. Wang, "Enhancing risk management by partnering in international EPC projects: perspective from evolutionary game in Chinese construction companies," Sustainability, vol. 11, no. 19, Article ID 5332, 2019.

[4] R. Singh, "Delays and cost overruns in infrastructure projects: extent, causes and remedies," Economic and Political Weekly, vol. 45, no. 21, pp. 43-54, 2010.

[5] R. Sacks, C. Eastman, G. Lee, and P. Teicholz, BIM Handbook: A Guide to Building Information Modeling for Owners, Designers, Engineers, Contractors, and Facility Managers, John Wiley \& Sons, New York, NY, USA, 2018.

[6] M. Jiang, Y. Cheng, T. Lei, and Z. Liu, "Intelligent construction, digital modeling of the future" Internet+ BIM service EPC project-— take the exhibition center of national cybersecurity center for education and innovation project as an example," IOP Conference Series: Earth and Environmental Science, vol. 719, no. 2, Article ID 022043, 2021.

[7] Y. Y. Al-Ashmori, I. Othman, Y. Rahmawati et al., "BIM benefits and its influence on the BIM implementation in Malaysia," Ain Shams Engineering Journal, vol. 11, no. 4, pp. 1013-1019, 2020.

[8] T. Kouider, G. Paterson, and C. Thomson, "BIM as a viable collaborative working tool: a case study," in Proceedings of the 12th International Conference on Computer-Aided Architectural Design Research in Asia: Digitization and Globalization, pp. 57-68, Beijing, China, January 2007.

[9] C. Ponsard, M. Touzani, and A. Majchrowski, "Synthèse des méthodes de conduite de projets Big Data et des retours collectés lors de pilotes industriels," Ingénierie des Systèmes d'Information, vol. 23, no. 1, pp. 9-33, 2018.

[10] K. Liu, Y. Liu, H. Zhou, Y. Kou, Q. Ji, and D. Li, "Evolutionary game and numerical simulation of participants' collaborative behavior in integrated project delivery project," Alexandria Engineering Journal, vol. 60, no. 1, pp. 373-385, 2020.

[11] W. Shen, W. Tang, W. Yu et al., "Causes of contractors' claims in international engineering-procurement-construction projects," Journal of Civil Engineering and Management, vol. 23, no. 6, pp. 727-739, 2017.

[12] W. Lu, L. Zhang, and L. Zhang, "Effect of contract completeness on contractors' opportunistic behavior and the moderating role of interdependence," Journal of Construction Engineering and Management, vol. 142, no. 6, Article ID 04016004, 2016.

[13] T. D. Oesterreich and F. Teuteberg, "Behind the scenes: understanding the socio-technical barriers to BIM adoption through the theoretical lens of information systems research," Technological Forecasting and Social Change, vol. 146, pp. 413-431, 2019.

[14] L. Liao and E. A. L. Teo, "Critical success factors for enhancing the building information modelling implementation in building projects in Singapore," Journal of Civil Engineering and Management, vol. 23, no. 8, pp. 1029-1044, 2017.

[15] Y. Zhou, Y. Yang, and J.-B. Yang, "Barriers to BIM implementation strategies in China," Engineering Construction and Architectural Management, vol. 26, no. 3, pp. 554-574, 2019.

[16] R. Agarwal, S. Chandrasekaran, and M. Sridhar, Imagining Construction's Digital Future, McKinsey \& Company, London, UK, 2016.

[17] P. Gong, N. Zeng, K. Ye, and M. König, “An empirical study on the acceptance of $4 \mathrm{D}$ BIM in EPC projects in China," Sustainability, vol. 11, no. 5, Article ID 1316, 2019.
[18] K.-F. Chien, Z.-H. Wu, and S.-C. Huang, "Identifying and assessing critical risk factors for BIM projects: empirical study," Automation in Construction, vol. 45, pp. 1-15, 2014.

[19] Y. Ren, M. J. Skibniewski, and S. Jiang, "Building information modeling integrated with electronic commerce material procurement and supplier performance management system," Journal of Civil Engineering and Management, vol. 18, no. 5, pp. 642-654, 2012.

[20] S. Azhar, "Building information modeling (BIM): trends, benefits, risks, and challenges for the AEC industry," Leadership and Management in Engineering, vol. 11, no. 3, pp. 241-252, 2011.

[21] M. C. Georgiadou, "An overview of benefits and challenges of building information modelling (BIM) adoption in UK residential projects," Construction Innovation, vol. 19, no. 3, pp. 298-320, 2019.

[22] E. Alreshidi, M. Mourshed, and Y. Rezgui, "Factors for effective BIM governance," Journal of Building Engineering, vol. 10, pp. 89-101, 2017.

[23] R. Charef, S. Emmitt, H. Alaka, and F. Fouchal, "Building information modelling adoption in the European union: an overview," Journal of Building Engineering, vol. 25, Article ID 100777, 2019.

[24] C. Sun, H. Xu, and S. Jiang, "Understanding the risk factors of BIM technology implementation in the construction industry: an interpretive structural modeling (ISM) approach," Engineering Construction and Architectural Management, vol. 27, no. 10, pp. 3289-3308, 2020.

[25] L. Zheng, W. Lu, K. Chen, K. W. Chau, and Y. Niu, "Benefit sharing for BIM implementation: tackling the moral hazard dilemma in inter-firm cooperation," International Journal of Project Management, vol. 35, no. 3, pp. 393-405, 2017.

[26] A. Yang, M. Z. Han, Q. C. Zeng, and Y. H. Sun, “Adopting building information modeling (BIM) for the development of smart buildings: a review of enabling applications and challenges," Advances in Civil Engineering, vol. 2021, Article ID 8811476, 26 pages, 2021.

[27] H. Yuan and Y. Yang, "BIM adoption under government subsidy: technology diffusion perspective," Journal of Construction Engineering and Management, vol. 146, no. 1, Article ID 04019089, 2020.

[28] J. Sun and L. Wang, "The interaction between BIM's promotion and interest game under information asymmetry," Journal of Industrial and Management Optimization, vol. 11, no. 4, pp. 1301-1319, 2015.

[29] D. Runrun and W. C. Richards, "Network evolution simulation of cooperation relationship in two phase project of Zhengzhou airport based on BIM," Journal of Intelligent and Fuzzy Systems, vol. 34, no. 2, pp. 1187-1192, 2018.

[30] Y. Du, H. Zhou, Y. Yuan, and H. Xue, "Exploring the moral hazard evolutionary mechanism for BIM implementation in an integrated project team," Sustainability, vol. 11, no. 20, p. 5719, 2019.

[31] Y. Y. Wang, H. Ren, and F. R. Ji, "Cooperative innovation evolutionary game analysis of industrialized building supply chain," Applied Mechanics and Materials, vol. 878, pp. 213218, 2018.

[32] G. Zhu, G. Pan, and W. Zhang, "Evolutionary game theoretic analysis of low carbon investment in supply chains under governmental subsidies," International Journal of Environmental Research Public Health, vol. 15, no. 11, p. 2465, 2018.

[33] T. Liu, Y. Deng, and F. Chan, "Evidential supplier selection based on DEMATEL and game theory," International Journal of Fuzzy Systems, vol. 20, no. 4, pp. 1321-1333, 2018. 
[34] T. Ouariachi, W. J. Elving, and F. Pierie, "Playing for a sustainable future: the case of We Energy Game as an educational practice," Sustainability, vol. 10, no. 10, 2018.

[35] P. D. Taylor and L. B. Jonker, "Evolutionary stable strategies and game dynamics," Mathematical Biosciences, vol. 40, no. 1-2, pp. 145-156, 1978.

[36] D. Friedman, "On economic applications of evolutionary game theory," Journal of Evolutionary Economics, vol. 8, no. 1, pp. 15-43, 1998.

[37] T. T. Lam, L. Mahdjoubi, and J. Mason, “A framework to assist in the analysis of risks and rewards of adopting BIM for SMEs in the UK," Journal of Civil Engineering and Management, vol. 23, no. 6, pp. 740-752, 2017.

[38] A. Tezel, M. Taggart, L. Koskela, P. Tzortzopoulos, J. Hanahoe, and M. Kelly, "Lean construction and BIM in small and medium-sized enterprises (SMEs) in construction: a systematic literature review," Canadian Journal of Civil Engineering, vol. 47, no. 2, pp. 186-201, 2020. 